\title{
A polyketide biosynthetic gene cluster from Streptomyces antibioticus includes a LysR-type transcriptional regulator
}

\author{
Victoria Colombo, † Maria Fernández-de-Heredia \\ and Francisco Malpartida
}

Centro Nacional de Biotecnologia, Campus de la Universidad Autónoma de Madrid, 28049 Cantoblanco, Madrid, Spain
Author for correspondence: Francisco Malpartida. Tel: +34 91 5854548. Fax: +34 915854506. e-mail:fmalpart@cnb.uam.es

\begin{abstract}
In the search for Type II polyketide synthases (PKSs) a DNA fragment was isolated from Streptomyces antibioticus ATCC 11891 (a producer of oleandomycin). DNA sequencing of the cloned fragment revealed six complete ORFs whose deduced products showed similarities to those of other genes known to be involved in polyketide biosynthesis. Several $S$. coelicolor strains mutated in different steps of actinorhodin biosynthesis (actl, actIII, act $V_{A}$ and actVII) were complemented by the cloned genes, suggesting that the isolated genes encode an aromatic polyketide of unknown structure and function. The cluster also contains a putative LysR-type transcriptional regulator (ORF0), which controls PKS gene expression in a heterologous host. DNA binding assays and transcriptional analysis suggest that the pathway-specific regulator for actinorhodin biosynthesis (actII-ORF4) is also involved in the expression of the cloned PKS in the host strain.
\end{abstract}

Keywords: actII-ORF4, actinorhodin, antibiotic, heterologous complementation, regulation

\section{INTRODUCTION}

Streptomyces spp. are soil bacteria with the ability to produce many biologically active products. Many of these compounds have important applications in human medicine (as antibacterial, antitumour or antifungal agents, immunomodulators, etc.) and in agriculture (as growth promoters and agents for plant protection amongst others). Some of them belong to a large class of metabolites, polyketides, that share with fatty acids a common pattern of biosynthetic steps via the successive condensation of simple carboxylic acid metabolites. The key enzyme in this pathway is polyketide synthase (PKS). Due to the possibility of using different starter and extender units and the introduction or not of reductive and cyclization steps, the end products can have a great variety of chemical structures. Two structural types of complex enzymes (Type I multifunctional proteins and Type II multienzyme complexes)

†Present address: Department of Molecular Microbiology, John Innes Centre, Colney Lane, Norwich NR4 7UH, UK.

Abbreviation: PKS, polyketide synthase.

The GenBank accession number for the sequence reported in this paper is Y19177. can be found among the different PKSs (for a review, see Hopwood, 1997). Several sets of genes for PKSs have been cloned and sequenced, for example actinorhodin (Malpartida \& Hopwood, 1984), daunorubicin (Stutzman-Engwall \& Hutchinson, 1989; Otten et al., 1995), granaticin (Sherman et al., 1989; Ichinose et al., 1998), tetracenomycin (Motamedi \& Hutchinson, 1987; Decker \& Hutchinson, 1993), mithramycin (Lombó et al., 1996, 1997) and landomycin (Westrich et al., 1999).

The clusters encoding different metabolic steps for a particular biosynthetic pathway usually include specific regulatory genes. In most cases such regulatory genes are positive regulators, such as those for actinorhodin (actIIORF4; Fernández-Moreno et al., 1991), undecylprodigiosin (redD; Narva \& Feitelson, 1990), daunorubicin (dnrI; Stutzman-Engwall et al., 1992) and mithramycin (mtmR; Lombó et al., 1999), among others. These pathway-specific regulators have been recently grouped within the SARP family (Wietzorrek \& Bibb, 1997), a group of Streptomyces regulatory proteins involved in the transcriptional regulation of antibiotic biosynthetic genes. The pathway-specific regulator is also interconnected with other aspects of Streptomyces physiology, such as morphological differentiation or carbon metabolism (Bibb, 1996; Chakraburtty et al., 
1996; Martínez-Costa et al., 1996). The mechanisms to globally regulate these complex processes in Streptomyces have been a topic for extensive analysis in several laboratories, giving rise to the isolation of several structurally different genes, such as bldA (Lawlor et al., 1987), the two-component systems afsR/afsK (Hong et al., 1991) and afsQ1/afsQ2 (Ishizuka et al., 1992), and abaB (Scheu et al., 1997).

The characterization of genes encoding polyketide biosynthesis is interesting for two reasons: on the one hand, the cloned biosynthetic genes can be useful to make libraries for combinatorial biosynthesis (Hopwood, 1997); on the other hand they might provide tools to overcome one of the limiting steps for antibiotic production, such as the control gene(s) for antibiotic biosynthetic pathways (Strauch et al., 1991). This paper describes the isolation and some preliminary characterization of a cluster of polyketide biosynthetic genes from Streptomyces antibioticus and a transcriptional regulatory gene linked to the cluster. We believe that these studies on the understanding of the basis of the regulation of antibiotic production in Streptomyces could contribute to improve our knowledge of this complicated control network.

\section{METHODS}

Bacterial strains. The Escherichia coli strains used were JM101

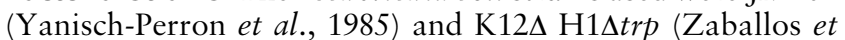
al., 1987) for subcloning and as expression host, respectively. Streptomyces antibioticus ATCC 11891 was used as a source of DNA for making the gene library. 'Streptomyces lividans' TK21 (Davis \& Chater, 1990) was used as primary recipient for the cloned genes and Streptomyces coelicolor strains (listed in Table 1) were used for functional characterization of the cloned biosynthetic genes.

Plasmids and bacteriophages. The E. coli vectors used were pUC18 and pUC19 (Yanisch-Perron et al., 1985) for subcloning and pAZe3ss (Zaballos et al., 1987) for expression. The E. coli M13mp18 and M13mp19 derivative phages (Yanisch-Perron et al., 1985) were used for DNA sequencing. The gene library was constructed in $\lambda$ EMBL4 (Frichauf et al., 1983).

The Streptomyces plasmid vector was the low-copy-number SCP2 derivative pIJ941 (Lydiate et al., 1985); its derivatives were those depicted in Fig. 1. pVR22 was constructed in several steps. First the EcoRI (3)-BamHI (5) fragment was cloned in pUC19, the 264 bp internal fragment was removed by digesting the resulting plasmid with EspI and BstEII, endfilled with the Klenow fragment of DNA polymerase and finally ligated. In the second step, the entire chromosomal insert of ant 1 was rescued by partial digestion with EcoRI and cloned into the EcoRI site of pUC18; its XbaI (4)-XbaI (polylinker fragment of pUC18) sequence was used to replace the XbaI (4)-Bam HI (5) fragment of the construction obtained in the first step, giving rise to a final recombinant plasmid carrying the truncated ORF0 and ORFs $1-4$. This plasmid was then cloned into pIJ941.

Construction of a gene library. Total DNA from S. antibioticus was partially digested with Sau3A and sizefractionated using a sucrose gradient. Fractions with a mean size between 16 and $25 \mathrm{~kb}$ were pooled and ligated into $\lambda$ EMBL4 (Frichauf et al., 1983). The ligation mixture was in vitro-packaged using the Promega $\lambda$ DNA Packaging System, following the manufacturer's recommendations.

DNA sequencing. DNA sequencing was carried out by using the dideoxy-chain termination method (Sanger et al., 1977). We used the 7-deaza-dGTP reagent kit from USB using the conditions recommended by the manufacturer. Convenient DNA fragments were previously cloned in either M13mp18 or M13mp19 vectors from suitable restriction fragments. Identification of DNA sequence in S1 protection experiments was carried out by the Maxam \& Gilbert (1980) method.

Computer analysis of sequences. The DNA sequence was analysed using the software programs of the University of Wisconsin Genetic Computer Group (Devereux et al., 1984). For analysis of ORFs we used CODONPREFERENCE with a codon usage table made from 100 Streptomyces genes (Wright $\&$ Bibb, 1992). Comparisons of sequences were made against the EMBL nucleic acid database and the SWISS-PROT database by using FASTA and TFASTA.

DNA and RNA manipulations. For isolation, cloning and manipulation of nucleic acids, the methods of Hopwood et al. (1985) were used for Streptomyces spp. and of Maniatis et al. (1982) for E. coli. For high-resolution S1 mapping, the method of Murray (1986) was used. The growth medium was liquid SY inoculated with pre-germinated spores (Hopwood et al., 1985); RNA preparations were made at several time points as indicated.

Expression of ORF0 in E. coli. ORF0 protein was overproduced in E. coli by using the pAZe3ss expression system (Zaballos et al., 1987). The translation start codon was changed by using PCR. PCR amplifications (Saiki et al., 1988) were carried out with an oligonucleotide carrying an NcoI site at the ATG

Table 1. S. coelicolor strains used in this work

\begin{tabular}{|c|c|c|}
\hline Strain & Mutant alleles and plasmids status & Reference \\
\hline TK17 & proA1 argA1 strA1 actI-118 redC-1 SCP2 ${ }^{-}$ & Feitelson \& Hopwood (1983) \\
\hline TK18 & uraA1 $\arg A 1$ strA1 redE-60 actIII-141 redC-1 SCP1- SCP2- & Feitelson \& Hopwood (1983) \\
\hline TK16 & $\arg A 1$ guaA1 actIV-117 redA-59 SCP1- SCP2- & Feitelson \& Hopwood (1983) \\
\hline JF4 & proA1 argA1 uraA1 strA1 redE-60 act $V_{A}^{-109} \mathrm{SCP}^{-} \mathrm{SCP}^{-}$ & Feitelson \& Hopwood (1983) \\
\hline JF1 & $\arg A 1$ guaA1 redD-42 actII-177 SCP1- SCP2- & Feitelson \& Hopwood (1983) \\
\hline J1501 & hisA1 uraA1 strA1 $\mathrm{SCP} 1^{-} \mathrm{SCP} 2^{-} p g l^{-}$ & Chater et al. (1982) \\
\hline MAFM0195 & bisA1 uraA1 strA1 SCP1 ${ }^{-} \mathrm{SCP}^{-} p g l^{-} \Delta a c t I-\mathrm{ORF} 1$ & Martínez-Costa et al. (1996) \\
\hline MAFM218 & hisA1 uraA1 strA1 SCP1- SCP2- ${ }^{-} g l \Delta a c t$ & Arias et al. (1999) \\
\hline
\end{tabular}




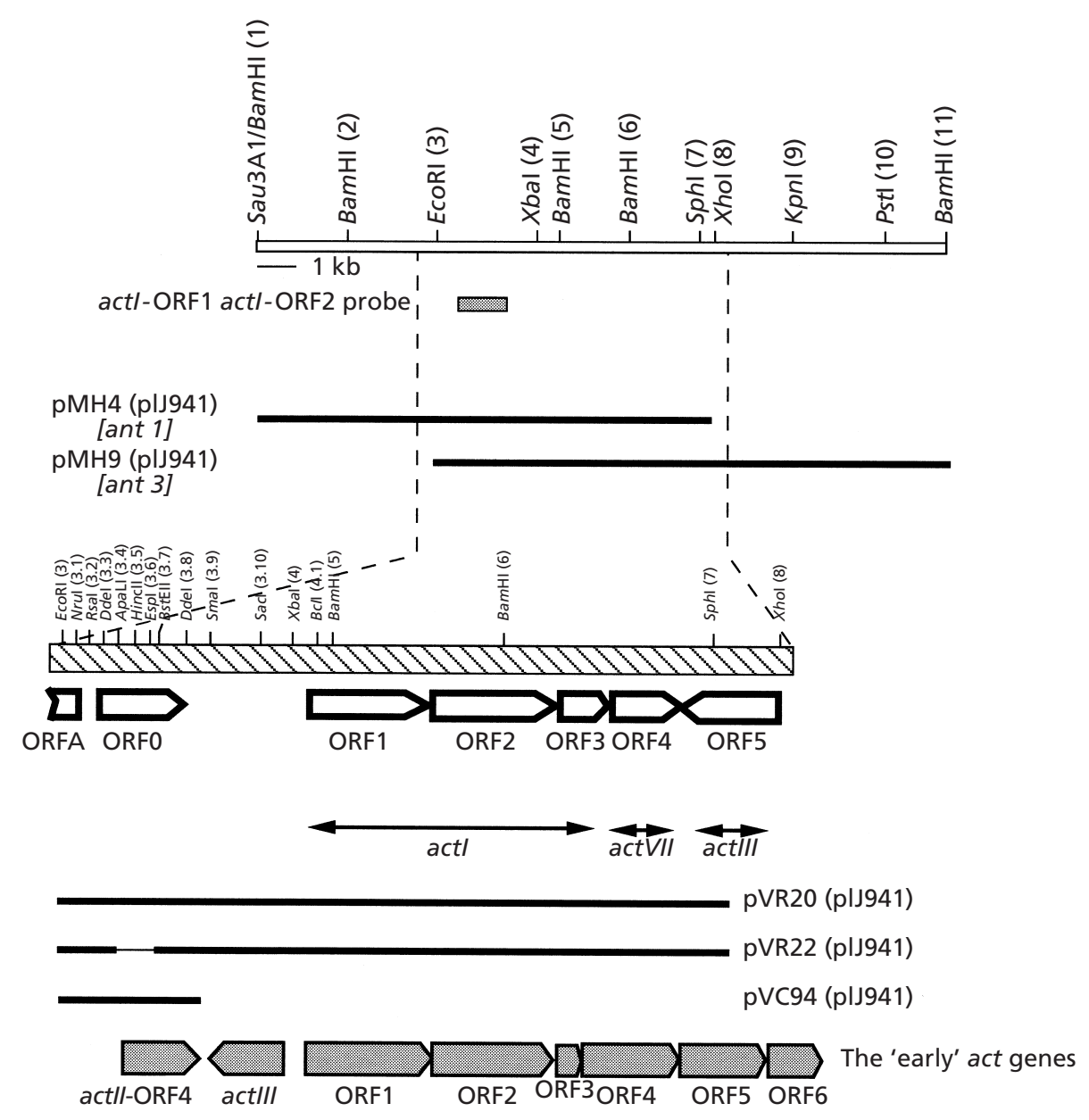

Fig. 1. Restriction map of the cloned PKS cluster. The sequenced region is shown as a hatched bar; the arrangement of the different ORFs is given below the restriction map of the enlarged region. DNA fragments (thick lines) cloned in pIJ941 are placed under the corresponding regions. The thin line in pVR22 shows the deleted region. At the bottom the organization of the 'early' and 'intermediate' act genes is shown for comparison with the cloned region.

translation start site and Thermostase (Promega) using the conditions suggested by the manufacturer. The engineered ORF0 gene was cloned into pAZe3ss to generate pVE3 and transformed into the recipient E. coli strain (Zaballos et al., 1987). Overnight cultures grown at $30^{\circ} \mathrm{C}$ in LB medium were used to inoculate fresh medium at a dilution rate of $2 \%$. After $1 \mathrm{~h}$ the cultures were induced by shifting the temperature to $42{ }^{\circ} \mathrm{C}$ and continuing growth for $2-3 \mathrm{~h}$. Almost all of the ORF0 protein from the induced culture (estimated to be nearly $20 \%$ of the total protein) was found in inclusion bodies. The cells were harvested by centrifugation and washed with a solution containing $10 \mathrm{mM}$ EDTA, $100 \mathrm{mM} \mathrm{NaCl}, 0.5 \mathrm{mM}$ PMSF, $10 \%$ glycerol, $1 \mathrm{mM}$ mercaptoethanol and $50 \mathrm{mM}$ Tris/ $\mathrm{HCl}, \mathrm{pH} 8$. The cells were resuspended in the same buffer and disrupted by sonication. Unbroken cells and heavy materials were fractionated by a preliminary centrifugation at $1000 \mathrm{~g}$. The insoluble material was recovered from the supernatant by centrifugation at $12000 \mathrm{~g}$. The pellet was washed once with a solution containing $1.5 \mathrm{M}$ urea, $0 \cdot 1 \mathrm{M}$ Tris/ $\mathrm{HCl}$ buffer, $\mathrm{pH} 8$, and finally solubilized with a solution containing $4.5 \mathrm{M}$ urea and $0 \cdot 1 \mathrm{M}$ Tris $/ \mathrm{HCl}, \mathrm{pH}$ 8. Most of the solubilized protein was ORF0, which was renatured by dialysis against a solution containing $1 \mathrm{M} \mathrm{NaCl}, 0 \cdot 005 \mathrm{M}$ DTT, $10 \%$ glycerol and $0.05 \mathrm{M}$ Tris $/ \mathrm{HCl}, \mathrm{pH}$. This material was used for further analysis.

Gel retardation assays. The probes were end-labelled with $[\alpha-$ ${ }^{32}$ P]dCTP and Klenow fragment. Labelled DNA (2000 c.p.m.) was incubated for $15 \mathrm{~min}$ at room temperature with the purified ORF0 protein. The incubation mixtures contained (in a total volume of $20 \mu \mathrm{l}$ ) $0.3 \mathrm{M} \mathrm{NaCl}, 0 \cdot 015 \mathrm{M}$ Tris/HCl, $\mathrm{pH} 8$, $0 \cdot 0015 \mathrm{M}$ DTT, $1 \mu \mathrm{g}$ poly-dIdC and $35 \%$ glycerol with the indicated amount of ORF0 protein. Protein-DNA complexes and free DNA were resolved on $5 \%$ polyacrylamide gels. After electrophoresis, the gels were dried and analysed by autoradiography.

DNase I footprinting. The EcoRI (3)-RsaI (3.2) fragment was used as probe. The fragment was previously cloned in M13mp18 and M13mp19 to obtain both strands. The direct primer (USB) was labelled with $\left[\gamma_{-}{ }^{32} \mathrm{P}\right] \mathrm{ATP}$ and with the cold reverse primer used to amplify by PCR. The reactions were carried out in $60 \mu \mathrm{l}$ of the mixture described above for the gel retardation assays. After incubation, $50 \mathrm{ng}$ DNase I was added to each reaction mixture. The DNA was precipitated and applied along with the dideoxy DNA sequencing ladders to a $6 \%$ polyacrylamide gel. Sequencing reactions on the same 
probes were also applied to the gels. After electrophoresis, the gels were dried and analysed by autoradiography.

\section{RESULTS}

\section{Cloning and DNA sequence of polyketide biosynthetic genes}

The gene library constructed in $\lambda$ EMBL4 (see Methods) was screened using pIJ2345 as probe (a pBR322-derived vector, containing the PKS from the actinorhodin cluster; Malpartida \& Hopwood, 1984). Two overlapping clones (ant1 and ant3) were isolated. These clones cover a chromosomal region of $17 \mathrm{~kb}$ from $S$. antibioticus (Fig. 1). The region hybridizing to the actinorhodin PKS was located and the DNA sequence of a $7 \mathrm{~kb}$ fragment was determined. Computer analysis of the DNA sequence revealed a set of 5 ORFs transcribed in the same direction from left to right (ORF0-4; Fig. 1), flanked by two ORFs oriented in the opposite direction (ORFA and ORF5 at the left and right hand ends, respectively). ORF1 appears to be translationally coupled with ORF2, overlapping by $4 \mathrm{bp}$. ORF2, 3, 4, 5, $A$ and 0 are preceded by putative ribosome-binding sites. The corresponding molecular masses of the deduced products would be (kDa): ORF1 (423 aa), 44.7; ORF2 (405 aa), 42.3; ORF3 (86 aa), 9·1; ORF4 (318 aa), 34.7; ORF5 (261 aa), 27.5; ORF0 (308 aa), 32.4. ORFA was truncated and only its $\mathrm{N}$ terminus was sequenced. There is a $48 \mathrm{bp}$ untranslated segment between ORF2 and ORF3, 106 bp between ORF3 and ORF4, and 1168 bp between ORF0 and ORF1 (Fig. 1).

Comparison of the deduced products of the ORFs with sequences in the databases showed high similarities with proteins known to be involved in the early steps of polyketide biosynthesis. ORF1, ORF2 and ORF3 show strong similarities with gene products related to either fatty acid or polyketide biosynthesis from different organisms, and could correspond to ketosynthase (or $\mathrm{KS} \alpha$ ), chain length factor (or $\mathrm{KS} \beta$ ) and acyl carrier protein, components of a 'minimal' PKS (McDaniel et al., 1994). The best scores were obtained with the gra $(87,61$ and $65 \%$ identity to ORF1, ORF2 and ORF3, respectively; Sherman et al., 1989), act (76, 59 and 50\% identity, respectively; Fernández-Moreno et al., 1992) and $t c m$ (69, 50 and $46 \%$ identity, respectively; Bibb et al., 1989) homologues. ORF2 and ORF3 contain conserved motifs (encoding cysteine and glutamine, respectively) that have been reported as active site motifs in homologous ketosynthase and chain length factors (Bisang et al., 1999). The translated product of ORF4 shows end-to-end similarities with Gra-ORF4 $(60 \%$ identity) and ActI-ORF4 (49\% identity; aromatases) (Sherman et al., 1991; Fernández-Moreno et al., 1992). The N-terminal sequence of ORFA also shows similarities to the dehydrase domain of the same aromatases. The translated product of ORF5 revealed strong similarities with the products of the actIII $(72 \%$; Hallam et al., 1988) and gra-ORF5 (84\%; Sherman et al., 1989) genes and is thus likely to encode a ketoreductase (Hallam et al., 1988; Bartel et al., 1990).
The deduced product of ORF0 has significant similarities to members of the LysR family, known as transcriptional regulators (Schell, 1993). The members of this family have high similarities within the $\mathrm{N}$ terminal domain - they contain a characteristic helixturn-helix DNA-binding domain (which is present in ORF0) - but lower, if any, similarities along the Cterminal domain (involved in the binding to different ligands). Nevertheless, ORF0 shows $30 \%$ identity endto-end to NodD proteins, which are involved in the recognition and response to flavonoids (members of the polyketide family; Downie \& Johnson, 1986).

\section{Expression and complementation analysis}

To characterize the putative function of the cloned genes, the DNA fragments from the $\lambda$ EMBL4 vector, ant 1 and ant3, were cloned on the low-copy-number vector pIJ941 to produce pMH4 and pMH9, respectively. These plasmids were introduced by transformation into several $S$. coelicolor act mutants and the transformants were tested for actinorhodin production. pMH4 restored actinorhodin production in mutants TK17 $\left(a c t I^{-}\right)$, B-140 $\left(\operatorname{actVII} I^{-}\right)$and JF4 $\left(a c t V_{A}^{-}\right)$, but not in TK18 $\left(\right.$ actIII $\left.^{-}\right)$and JF1 $\left(\right.$actII I $\left.^{-}\right)$. pMH9 restored actinorhodin production in mutants TK17 $\left(a c t I^{-}\right)$and TK18 (actIII $\left.{ }^{-}\right)$, but not in B-140 (actVII $\left.{ }^{-}\right)$, JF4 $\left(\operatorname{actV}_{A}{ }^{-}\right)$ and JF1 $\left(\right.$ actII I $\left.^{-}\right)$. The observed complementation with plasmids, after transformation of the corresponding $S$. coelicolor mutants, suggests that the cloned genes are involved in an unknown polyketide biosynthetic pathway.

For further characterization of the involvement of ORF0 in the expression of the cloned polyketide biosynthetic genes, several clones were constructed (see Fig. 1). The fragment containing ORF0-4 was subcloned into the low-copy-number vector pIJ941 to generate pVR20; pVR22 was generated by deleting from pVR20 the 264 bp EspI (3.6)-BstEII (3.7) fragment which is internal to ORF0 (see Methods). Both constructs were used to transform the $S$. coelicolor actI mutant MAFM0195 (see Table 1). Only pVR20 could restore actinorhodin production, suggesting that ORF0 is needed for expression of the cloned PKS, at least under heterologous conditions.

\section{Transcription of the cloned genes}

The transcriptional analysis of the cloned ORFs was determined by high-resolution S1 nuclease protection experiments. For ORF0 and ORFA determination, total S. antibioticus RNA was hybridized with the $318 \mathrm{bp}$ EcoRI (3)-DdeI (3.3) fragment (Fig. 1) labelled at either end. When the EcoRI (3) site was labelled, a $110 \mathrm{bp}$ protected fragment was seen after S1 digestion (data not shown), while a $185 \mathrm{bp}$ fragment was protected when the DdeI (3.3) site was labelled. These results show that two divergent transcripts could be generated in this region, one beginning $30 \mathrm{nt}$ upstream of the ORFA start codon and the other $81 \mathrm{nt}$ upstream of ORF0. This 
(a)

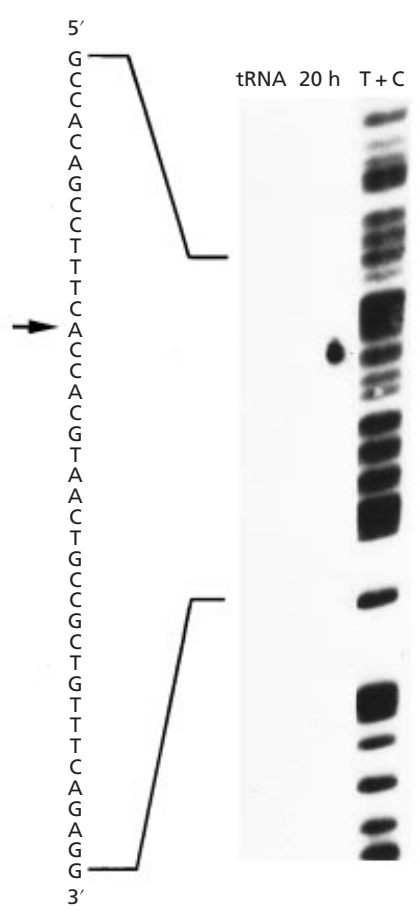

(b) (i)

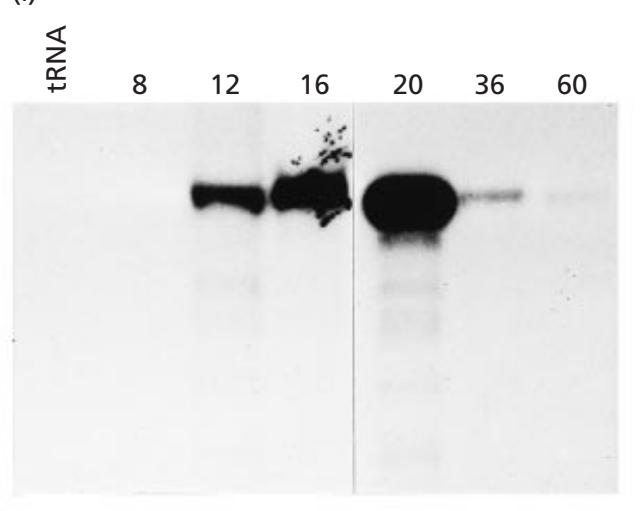

(iii)

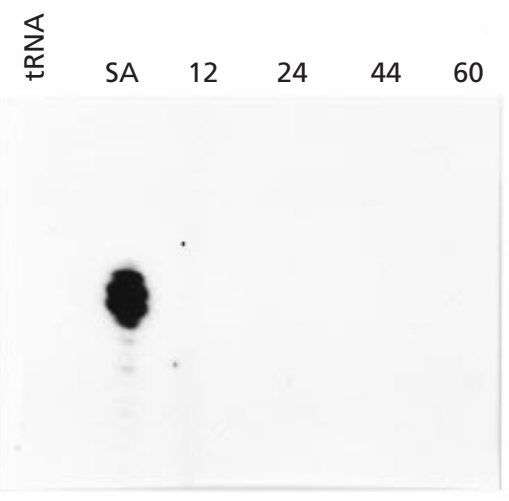

(ii)

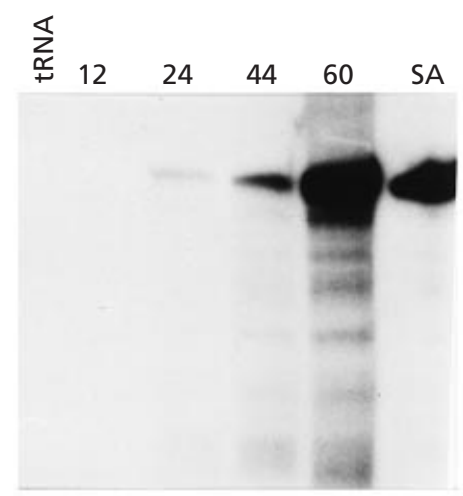

(iv)

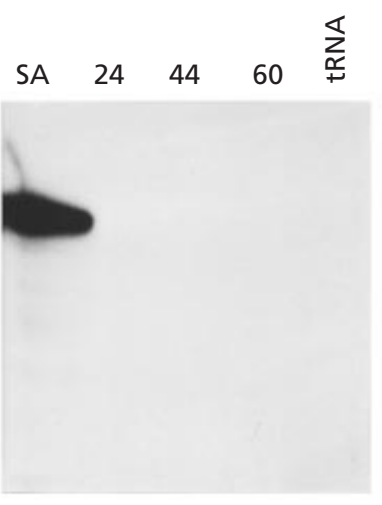

Fig. 2. Transcriptional characterization of the cloned ORFs. (a) Determination of the transcription start point for ORF1. The start point is indicated by an arrow, as derived from Maxam \& Gilbert sequencing reactions on the protected fragment. The RNA was extracted from a $20 \mathrm{~h}$ liquid culture of $S$. antibioticus. (b) Transcription pattern of ORF1 in several backgrounds. (i) Time course expression of the ORF1 transcript in S. antibioticus. RNAs were extracted from liquid cultures. (ii) Time course expression of ORF1 under heterologous conditions. The RNAs were extracted from S. antibioticus (SA) at $20 \mathrm{~h}$ and from S. coelicolor MAFM0195 carrying pVR20 (2) at the indicated time. (iii) Heterologous expression of the ORF1 transcript. RNAs were extracted from S. coelicolor MAFM0195, carrying pVR20 at $60 \mathrm{~h}$ (SA) and from the same strain carrying pVR22 at the indicated time. (iv) Heterologous expression of the ORF1 transcript in S. coelicolor lacking the actII-ORF4 gene. The RNAs were extracted from S. antibioticus (SA) at $20 \mathrm{~h}$ and from S. coelicolor MAFM218 carrying pVR20 at the indicated time.

arrangement is a typical feature which has been described for many other LysR-type transcriptional activators (Schell, 1993).

The transcriptional start point of ORF1 was determined by hybridizing total RNA with the 273 bp SacI (3.10)$B c l$ I (4.1) fragment, labelled at the $5^{\prime} B c l$ ( 4.1$)$ site. A $185 \mathrm{bp}$ protected fragment was obtained after S1 digestion, indicating the presence of a transcript initiating 70 nt upstream of the ORF1 start codon Fig. 2(a).

We further analysed the temporal expression of the cloned PKS gene by S1 nuclease protection experiments (Fig. 2b, i); the RNAs were obtained from cultures incubated at different times (see Methods). The probe was the 468 bp SacI (3.10)-BamHI (5) fragment labelled at the BamHI site. Maximal expression was detected at the earliest stages of growth, being almost undetectable after $36 \mathrm{~h}$. This result shows that transcription of ORF1 is temporally regulated. The same pattern was observed in S. coelicolor MAFM0195 carrying pVR20 (Fig. 2b, ii). Interestingly, no protected fragment was detected in the same strain carrying pVR22 (Fig. 2b, iii), suggesting that ORF0 is indeed involved in the regulation of transcription of the cloned PKS genes, in good agreement with the absence of complementation of the actl gene in this strain.

\section{Characterization of the ORFO protein}

From the previous experiment it was clear that ORF0 was needed for expression of the cloned PKS genes. It was interesting to analyse the mechanism involved in the control of PKS expression more deeply. Thus, the ORF0 protein was purified from E. coli cultures to test its functional activity. The protein, purified from inclusion bodies, was analysed for its possible DNAbinding activity by gel retardation assays. The ORF0-A intergenic region was chosen as the target sequence 


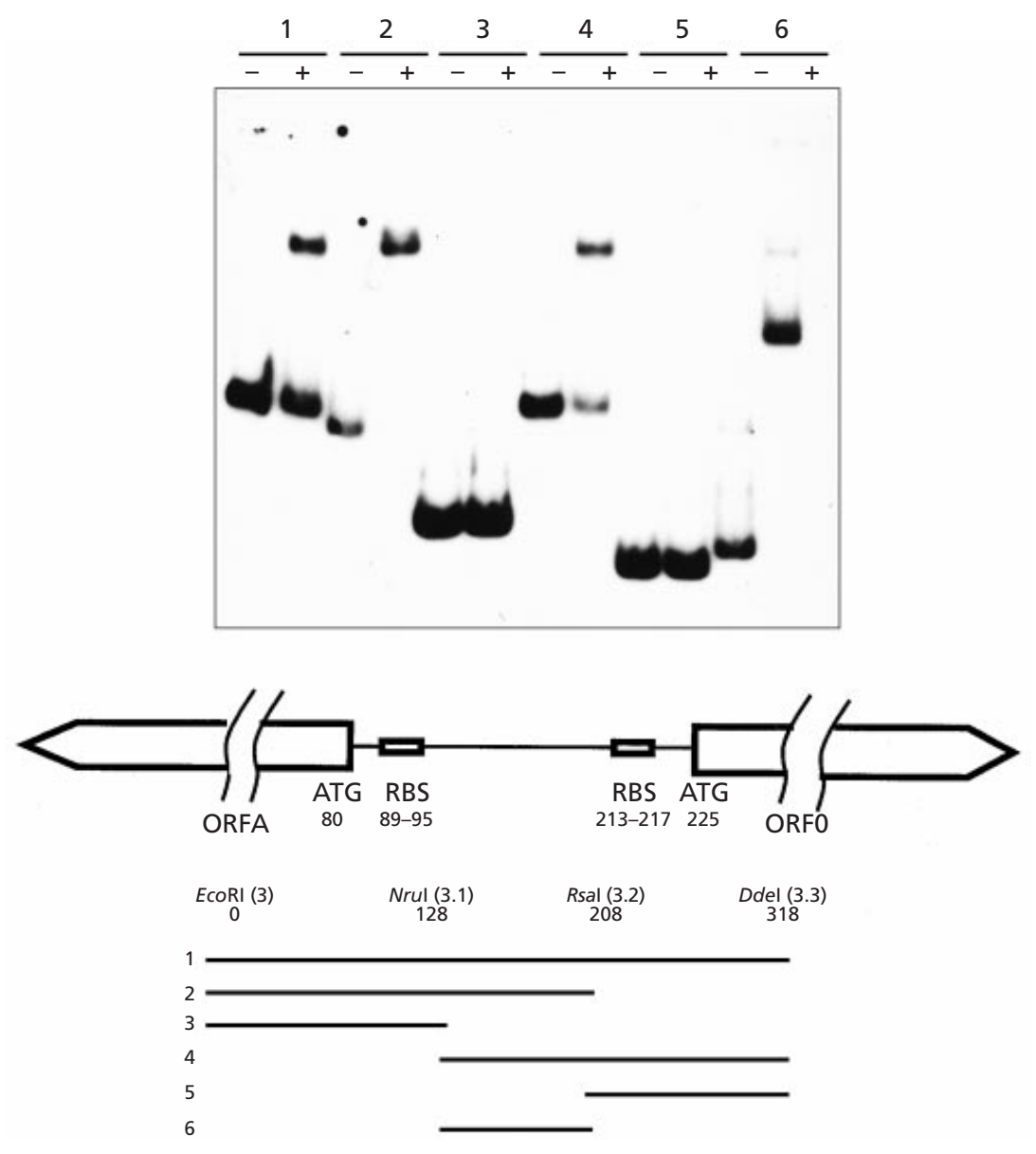

Fig. 3. Band-shift analysis to identify the target for the ORFO protein within the $O$ RFO-A intergenic region. The region was fractionated using the indicated restriction sites (lower part) and the resulting fragments (numbered) were resolved in a polyacrylamide gel (upper part; see Methods) without $(-)$ or after previous incubation with $500 \mathrm{ng}$ ORF0 protein $(+)$.

because most of the LysR regulators interact with the DNA region of their own promoter and thus regulate their own transcription. A set of overlapping DNA fragments was labelled as indicated in Methods and tested for interaction with the ORF0 protein. As shown in Fig. 3 a band-shift is clearly detected, suggesting that the intergenic region could be a target for the ORF0 protein and that the protein is functional and probably correctly folded even after renaturation from the urea solubilization step.

To locate the site of interaction between the ORF0 protein and the ORF0-A intergenic region more precisely, the 208 bp EcoRI (3)-RsaI (3.2) fragment was end-labelled and used in footprinting analysis. After incubation as indicated in Methods, two regions protected against DNase I digestion (covering 17 and $26 \mathrm{nt}$, respectively) were observed (Fig. 4a). The regions are separated by $3 \mathrm{nt}$ (Fig. 4b), a region hypersensitive to DNase I digestion. This finding suggests that the ORF0 protein would interact with this intergenic region. Similarly, the 1168 bp DNA fragment upstream of the PKS genes was tested as a possible target for the ORF0 protein in gel retardation assays. Surprisingly, no bandshift was detected with the promoter of the cloned PKS, suggesting that this DNA region is not a direct target for the ORF0 protein. This finding suggests that the ORF0 protein might have another target which would be needed for activation of the cloned PKS transcription.

\section{The actII-ORF4 promoter as target for the ORF4 protein}

The absence of interaction between the ORF0 protein and the PKS promoter suggests that the role of ORF0 in controlling PKS expression (as suggested by the complementation experiments) might be mediated by some other regulator. Accordingly, the ORF0 protein would activate such a putative regulator, the activation of which would result in expression of the PKS genes. The first obvious candidate was the pathway-specific positive regulator for actinorhodin biosynthesis (the actII-ORF4 gene). To test this idea, pVR20 was introduced by transformation into S. coelicolor PM218, a strain lacking most of the act cluster, including the actIIORF4 gene (Fig. 1b). Total RNA was hybridized with the 273 bp SacI (3.10)-BclI (4.1) fragment (Fig. 2b, iv) which was previously used to determine the transcriptional start point of ORF1. No protected fragment was observed, indicating that the cloned PKS was not expressed in S. coelicolor in the absence of the pathwayspecific regulator actII-ORF4. This finding strongly suggests that the expression of the cloned PKS, at least under heterologous conditions, is also dependent on the 
(a)

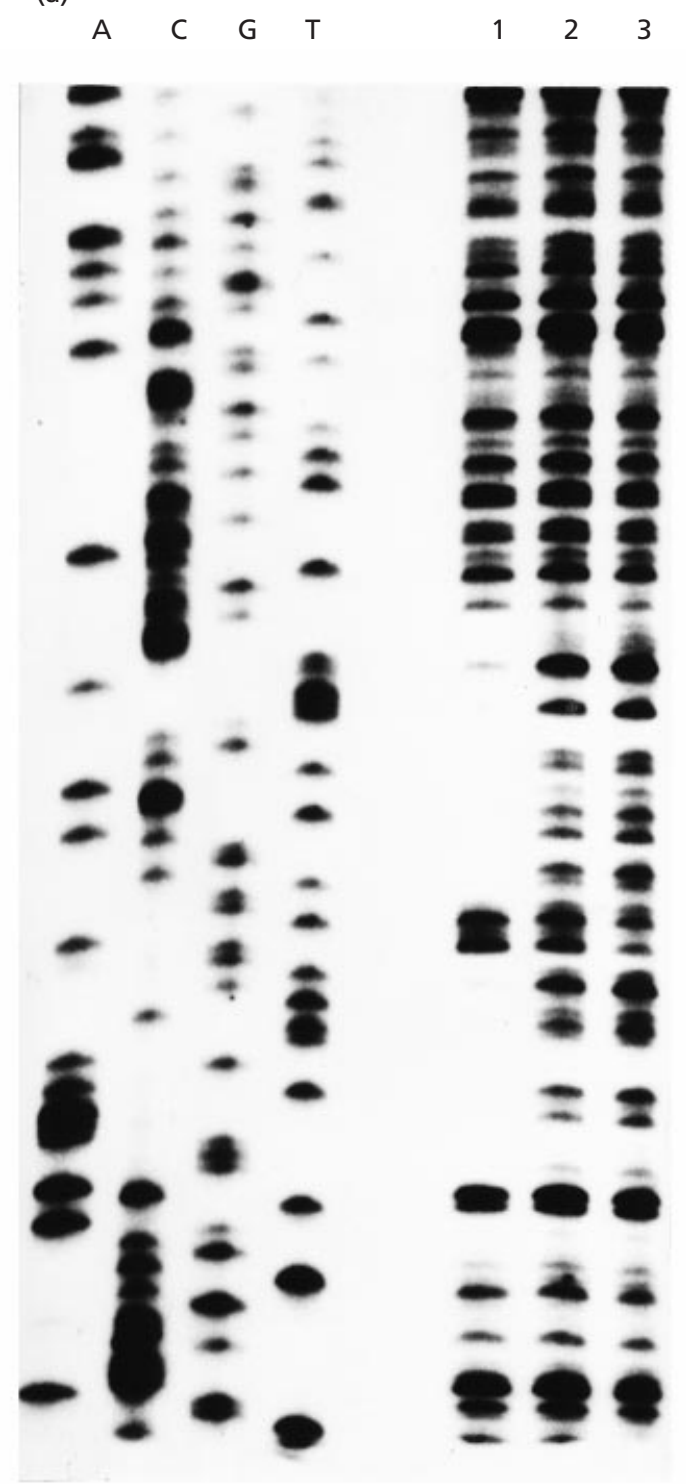

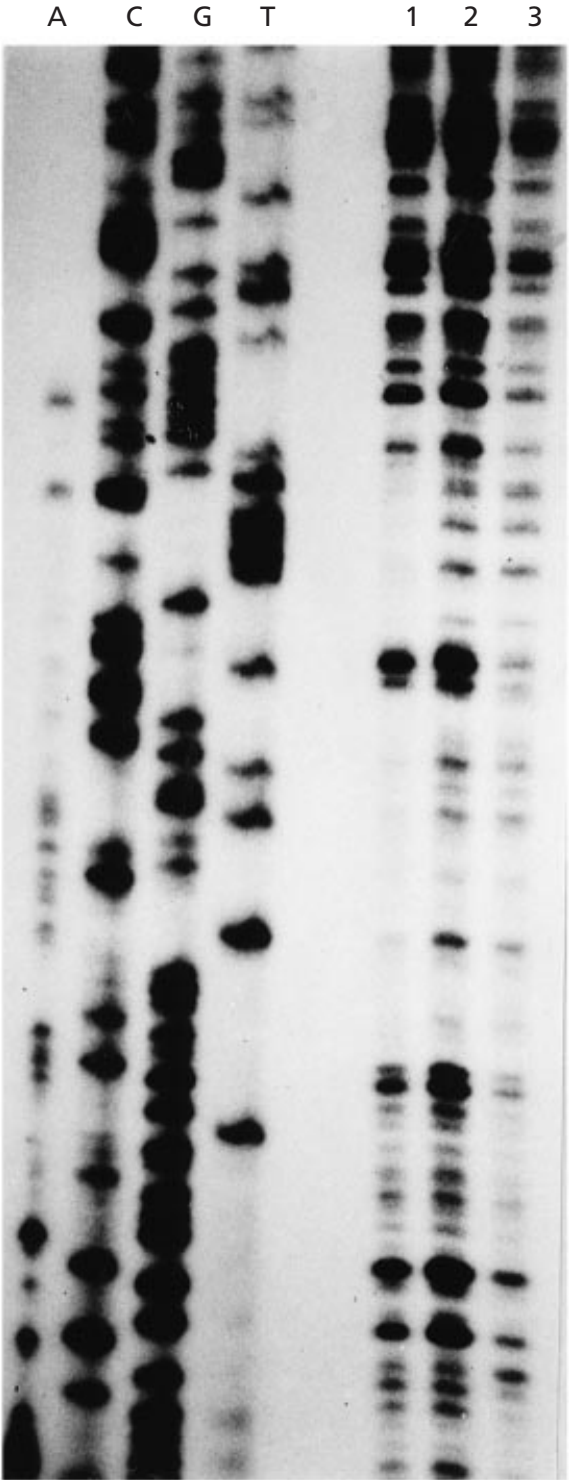

(b)

ORF0 transcript

ORFO transcript

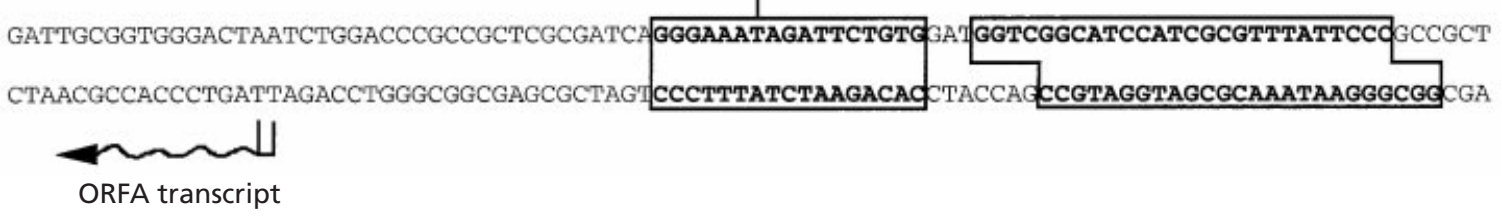

Fig. 4. DNase I footprinting analysis to identify the target of the ORFO protein. The conditions used for this activity are indicated in Methods. (a) Both strands, upper and lower (left and right panels, respectively) were tested. Lanes: 1, $1 \mu \mathrm{g}$ ORF0 protein; 2, $0.5 \mu \mathrm{g}$ ORF0; 3, no protein. (b) DNA sequence of the DNase I digestion-protected regions, represented by boxes. The beginning of the ORFO and ORFA transcripts are indicated by arrows.

actII-ORF4 gene in addition to ORF0. If this assumption is correct, then the ORF0 protein indeed interacts with the actII-ORF4 promoter.
To explore this possibility, the DNA-binding activity of the ORF0 protein was tested within the promoter region of the actII-ORF4 gene. The gel mobility shift assays 
(a) 0

$\begin{array}{lllllllll}50 & 100 & 150 & 200 & 250 & 300 & 350 & 400 & 450\end{array}$

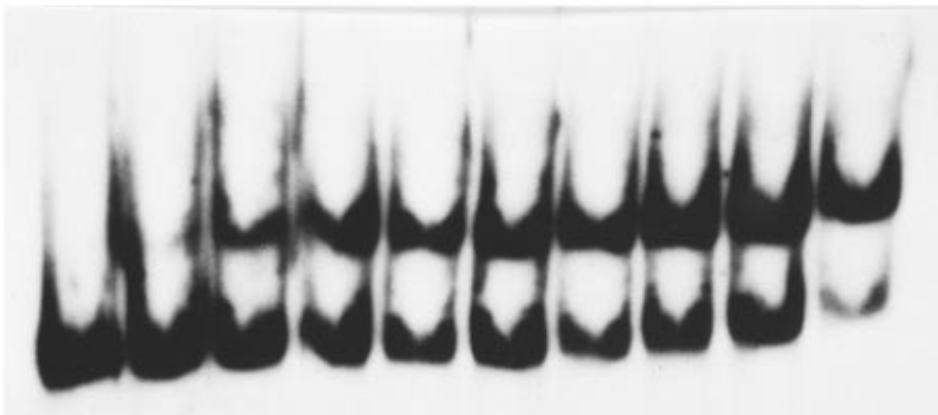

(c)

ORFO

GGAAATAGATTCTGGATGGTCGGCATCCA

actII-ORF

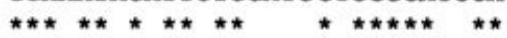

GGAGATCGCTTGTG... GACGGCAAGCA

(b)

actll-ORF4 transcript

CAATAGGAGATCGCTTGTGACGGCAAGCACATTGAAATCTGTTGAGTA GGCCTGTTATTGTCGCCCCAGGAGACGGAGAATCTCGACGGGGGCGCAGATG GTTATCCTCTAGCGAACACTGCCGTTCGAGTAACTTTAGACAACTCAT CCGGACAATAACAGCGGGGTCCTCTGCCTCTTAGAGCTGCCCCCGCGTCTAC

Fig. 5. Band shift analysis of the ORFO protein within the actll-ORF4 promoter region. (a) Gel mobility shift assays were carried out with a $463 \mathrm{bp}$ end-labelled DNA fragment and different amounts (ng as indicated above each lane) of the ORF0 protein. (b) Transcription initiation site of the actII-ORF4 transcript. (c) Homology between actll-ORF4 promoter and the regions protected against DNase I digestion in the ORFO-A intergenic region.

were carried out with a 463 bp end-labelled DNA fragment and different amounts of the ORF0 protein (Fig. 5a). The results clearly show that the ORF0 protein interacts with this region, suggesting that this might be another target for the ORF0 protein. Interestingly, immediately upstream of the -35 region of the actIIORF4 promoter (Fig. 5b) there is a region with partial homology to the target region of the ORF0 promoter (see Fig. 5c) which was previously determined in the DNase foot-printing assays. These sequences are not present within the PKS promoter. These results clearly suggest that an additional target for the ORF0 protein would be located immediately upstream of the actIIORF4 promoter and thus would result in activation of actII-ORF4 transcription. It is noteworthy that ORF0, cloned in $\mathrm{pIJ} 941$, increased actinorhodin production in S. coelicolor J1501 by a factor of about two (data not shown).

From all these experiments, we can conclude that ORF0, at least under heterologous conditions, controls PKS expression through the actII-ORF4 gene. Whether or not this scheme also applies in S. antibioticus needs further work.

\section{DISCUSSION}

A gene cluster was isolated from S. antibioticus, a strain known to produce the macrolide antibiotic oleandomycin and to contain the Type I PKS genes (Swan et al., 1994). As in many other actinomycetes, S. antibioticus 11891 contains several actI-hybridizing fragments
(Malpartida et al., 1987); the possibility that some of them are involved in the biosynthesis of well known, spore-associated pigments (Davis \& Chater, 1990; Blanco et al., 1992, 1993) cannot be ruled out. Nevertheless, the physical arrangement of the cloned gene cluster described in this paper, and the complementation pattern obtained with the act mutants, suggest that this gene cluster might well be involved in the production of some unidentified polyketide metabolite rather than the spore-associated pigment produced by the whiE cluster and its homologues. Whether or not this putative compound might have antimicrobial activity needs further analysis. The absence of an efficient method for transformation of S. antibioticus 11891 makes this question very difficult to resolve.

The work presented in this paper clearly shows that, in $S$. antibioticus, transcription of the PKS genes is temporally regulated, a feature similar to other PKS genes (Bibb, 1996). The PKS genes from S. antibioticus seem to be regulated by a LysR-type transcriptional regulator; the evidence presented in this paper strongly suggests that, in addition to this regulator, the control of PKS expression is also mediated by some other transcriptional regulator of the SARP family (Wietzorrek \& Bibb, 1997), similar to actII-ORF4, because the ORF0 protein recognizes the actII-ORF4 promoter region as a target. A similar LysR-type transcriptional regulator was found adjacent to the act cluster in S. coelicolor (Martínez-Costa et al., 1999). It was shown to negatively control actinorhodin production in 'S. lividans', but unlike the ORF0 protein, the LysR-type regulator of $S$. 
coelicolor does not bind to the actII-ORF4 promoter region.

An interesting feature of LysR transcriptional regulators is that some of them behave as sensors of physiological changes and can bind directly to different kind of molecules. The strong similarities between the $\mathrm{C}$ terminus of the ORF0 protein and NodD domains in Rhizobium that interact with flavonoids (members of the polyketide family; Downie \& Johnson, 1986) lead us to suggest, as an attractive hypothesis, a putative role of the encoded polyketide in the autoregulation of the ORF0 gene and the entire cluster. Further characterization of the cloned genes and the surrounding region will be an interesting issue for the future to clarify the complex network of regulatory signals in antibiotic regulation.

In this context this biosynthetic cluster might offer an excellent opportunity for exploring the intricate mechanisms that modulate gene expression leading to secondary metabolite production in Streptomyces.

\section{ACKNOWLEDGEMENTS}

This work was supported by Grants from the Spanish CICYT (BIO1999-1223) and the European Union (BIO2-CT94-2067 and ERBCHRXCT940570).

\section{REFERENCES}

Arias, P., Fernández-Moreno, M. A. \& Malpartida, F. (1999). Characterization of the pathway-specific positive transcriptional regulator for actinorhodin biosynthesis in Streptomyces A3(2) as a DNA-binding protein. J Bacteriol 181, 6958-6968.

Bartel, P. L., Zung, C. H., Lampel, J. S., Dosch, D. C., Connors, N. C., Strohl, W. R., Beale, J. J. M. \& Floss, H. G. (1990). Biosynthesis of anthraquinones by interspecific cloning of actinorhodin biosynthesis genes in streptomycetes: clarification of actinorhodin gene function. J Bacteriol 172, 4816-4826.

Bibb, M. (1996). The regulation of antibiotic production in Streptomyces coelicolor A3(2). Microbiology 142, 1335-1344.

Bibb, M. J., Biro, S., Motamedi, H., Collins, J. F. \& Hutchinson, C. R. (1989). Analysis of the nucleotide sequence of the Streptomyces glaucescens tcm I gene provides key information about the enzymology of polyketide antibiotic biosynthesis. EMBO J 8, 2727-2736.

Bisang, C., Long, P. F., Cortés, J. \& 7 other authors (1999). A chain initiation factor common to both modular and aromatic polyketide synthases. Nature 401, 502-505.

Blanco, G., Pereda, A., Méndez, C. \& Salas, J. A. (1992). Cloning and disruption of a fragment of Streptomyces halstedii DNA involved in the biosynthesis of a spore pigment. Gene 112, 59-65.

Blanco, G., Brian, P., Pereda, A., Méndez, C., Salas, J. A. \& Chater, K. F. (1993). Hybridization and DNA sequence analyses suggest an early evolutionary divergence of related biosynthetic gene sets encoding polyketide antibiotics and spore pigments in Streptomyces spp. Gene 130, 107-116.

Chakraburtty, R., White, J., Takano, E. \& Bibb, M. (1996). Cloning, characterization and disruption of a (p)ppGpp synthetase gene (relA) of Streptomyces coelicolor A3(2). Mol Microbiol 19, 357-368.

Chater, K. F., Bruton, C. J., King, A. A. \& Suárez, J. E. (1982). The expression of Streptomyces and Escherichia coli drug-resistance determinants cloned into the Streptomyces phage $\phi$ C31. Gene 19, 21-32.

Davis, N. K. \& Chater, K. F. (1990). Spore colour in Streptomyces coelicolor A3(2) involves the developmentally regulated synthesis of a compound biosynthetically related to polyketide antibiotics. Mol Microbiol 4, 1679-1691.

Decker, H. \& Hutchinson, C. R. (1993). Transcriptional analysis of the Streptomyces glaucescens tetracenomycin-C biosynthesis gene cluster. J Bacteriol 175, 3887-3892.

Devereux, J., Haeberli, P. \& Smithies, O. (1984). A comprehensive set of sequence analysis programs for the VAX. Nucleic Acids Res 12, 387-395.

Downie, J. A. \& Johnson, A. W. (1986). Nodulation of legumes by Rhizobium: the recognized roots? Cell 47, 153-154.

Feitelson, J. S. \& Hopwood, D. A. (1983). Cloning of a Streptomyces gene for an $\mathrm{O}$-methyltransferase involved in antibiotic biosynthesis. Mol Gen Genet 190, 394-398.

Fernández-Moreno, M. A., Caballero, J. L., Hopwood, D. A. \& Malpartida, F. (1991). The act cluster contains regulatory and antibiotic export genes, direct targets for transcriptional control by the bldA transfer RNA gene of Streptomyces coelicolor. Cell 66, 769-780.

Fernández-Moreno, M. A., Martínez, E., Boto, L., Hopwood, D. A. \& Malpartida, F. (1992). Nucleotide sequence and deduced function of a set of co-transcribed genes of Streptomyces coelicolor A3(2) including the polyketide synthase for the antibiotic actinorhodin. J Biol Chem 267, 19278-19290.

Frichauf, A. M., Lehrach, H., Poustka, A. M. \& Murray, N. (1983). Lambda replacement vectors carrying polylinker sequences. $J$ Mol Biol 170, 827-842.

Hallam, S. E., Malpartida, F. \& Hopwood, D. A. (1988). Nucleotide sequence, transcription and deduced function of a gene involved in polyketide antibiotic synthesis in Streptomyces coelicolor. Gene 74, 305-320.

Hong, S. K., Kito, M., Beppu, T. \& Horinouchi, S. (1991). Phosphorylation of the AfsR product, a global regulatory protein for secondary-metabolite formation in Streptomyces coelicolor A3(2). J Bacteriol 173, 2311-2318.

Hopwood, D. A. (1997). Genetic contribution to understanding polyketide synthase. Chem Rev 97, 2465-2497.

Hopwood, D. A., Bibb, M. J., Chater, K. F. \& 7 other authors (1985). Genetic Manipulation of Streptomyces: a Laboratory Manual. Norwich: John Innes Foundation.

Ichinose, K., Bedford, D. J., Bibb, M. J., Revill, W. P. \& Hopwood, D. A. (1998). The granaticin biosynthetic gene cluster of Streptomyces violaceoruber $\mathrm{Tü22:} \mathrm{sequence} \mathrm{analysis} \mathrm{and} \mathrm{expression}$ in a heterologous host. Chem Biol 5, 647-659.

Ishizuka, H., Horinouchi, S., Kieser, H. M., Hopwood, D. A. \& Beppu, T. (1992). A putative two-component regulatory system involved in secondary metabolism in Streptomyces spp. J Bacteriol 174, 7585-7594.

Lawlor, E. J., Baylis, H. A. \& Chater, K. F. (1987). Pleiotropic morphological and antibiotic deficiencies result from mutations in a gene encoding a tRNA-like product in Streptomyces coelicolor A3(2). Genes Dev 1, 1305-1310.

Lombó, F., Blanco, G., Fernández, E., Méndez, C. \& Salas, J. A. (1996). Characterization of Streptomyces argillaceus genes encoding a polyketide synthase involved in the biosynthesis of the antitumour mithramycin. Gene 172, 87-91.

Lombó, F., Siems, K., Braña, A. F., Méndez, C., Bindseil, K. \& Salas, J. A. (1997). Cloning and insertional inactivation of Streptomyces 
argillaceus genes involved in the earliest steps of biosynthesis of the sugar moieties of the antitumour polyketide mithramycin. $J$ Bacteriol 179, 3354-3357.

Lombó, F., Braña, A. F., Méndez, C. \& Salas, J. A. (1999). The mithramycin gene cluster of Streptomyces argillaceus contains a positive regulatory gene and two repeated DNA sequences that are located at both ends of the cluster. J Bacteriol 181, 642-647.

Lydiate, D. J., Malpartida, F. \& Hopwood, D. A. (1985). The Streptomyces plasmid SCP2*: its functional analysis and development into useful cloning vectors. Gene 35, 223-235.

McDaniel, R., Ebert-Khosla, S., Fu, H., Hopwood, D. A. \& Khosla, C. (1994). Engineered biosynthesis of novel polyketides: influence of a downstream enzyme on the catalytic specificity of a minimal aromatic polyketide synthase. Proc Natl Acad Sci USA 91, 11542-11546.

Malpartida, F. \& Hopwood, D. A. (1984). Molecular cloning of the whole biosynthetic pathway of a Streptomyces antibiotic and its expression in a heterologous host. Nature 309, 462-464.

Malpartida, F., Hallam, S. E., Kieser, H. M. \& 9 other authors (1987). Homology between Streptomyces genes coding for synthesis of different polyketides used to clone antibiotic biosynthetic genes. Nature 325, 818-821.

Maniatis, T., Fritsch, E. F. \& Sambrook, J. (1989). Molecular Cloning: a Laboratory Manual. Cold Spring Harbor, NY: Cold Spring Harbor Laboratory.

Martínez-Costa, O. H., Arias, P., Romero, N. M., Parro, V., Mellado, R. P. \& Malpartida, F. (1996). A relA/spoT homologous gene from Streptomyces coelicolor A3(2) controls antibiotic biosynthetic genes. J Biol Chem 271, 10627-10634.

Martínez-Costa, O. H., Martín-Triana, A. J., Martínez, E., Fernández-Moreno, M. A. \& Malpartida, F. (1999). An additional regulatory gene for actinorhodin production in Streptomyces lividans involves a LysR-type transcriptional regulator. $J$ Bacteriol 181, 4353-4364.

Maxam, A. M. \& Gilbert, W. (1980). Sequencing end-labelled DNA with base specific chemical cleavages. Methods Enzymol 65, 449-560.

Motamedi, H. \& Hutchinson, C. R. (1987). Cloning and heterologous expression of a gene cluster for the biosynthesis of tetracenomycin C, the anthracycline antitumour antibiotic of Streptomyces glaucescens. Proc Natl Acad Sci USA 84, 4445-4449.

Murray, G. M. G. (1986). Use of sodium trichloroacetate and mung bean nuclease to increase sensitivity and precision during transcript mapping. Annu Rev Biochem 158, 165-170.

Narva, K. E. \& Feitelson, J. S. (1990). Nucleotide sequence and transcriptional analysis of the redD locus of Streptomyces coelicolor A3(2). J Bacteriol 172, 326-333.

Otten, S. L., Liu, X. C., Ferguson, J. \& Hutchinson, C. R. (1995). Cloning and characterization of the Streptomyces peucetius $d n r \mathrm{QS}$ genes encoding a daunosamine biosynthesis enzyme and a glycosyl transferase involved in daunorubicin biosynthesis. $J$ Bacteriol 177, 6688-6692.

Saiki, R. K., Gelfand, D. H., Stoffel, S., Scharf, S. J., Higuchi, R., Horn, G. T., Mullis, K. B. \& Erlich, H. A. (1988). Primer-directed enzymatic amplification of DNA with a thermo-stable DNA polymerase. Science 239, 487-491.

Sanger, F., Nicklen, S. \& Coulson, A. R. (1977). DNA sequencing with chain-terminating inhibitors. Proc Natl Acad Sci US A 74, 5463-5467.

Schell, M. A. (1993). Molecular biology of the LysR family of transcriptional regulators. Annu Rev Microbiol 47, 597-626.

Scheu, A. K., Martínez, E., Soliveri, J. \& Malpartida, F. (1997). $a b a B$, a putative regulator for secondary metabolism in Streptomyces. FEMS Microbiol Lett 147, 29-36.

Sherman, D. A., Bibb, M. J., Simpson, T. J., Johnson, D., Malpartida, F., Fernández-Moreno, M. A., Martínez, E., Hutchinson, C. R. \& Hopwood, D. A. (1991). Molecular genetic analysis reveals a putative bifunctional polyketide cyclase/ dehydrase gene from Streptomyces coelicolor and Streptomyces violaceorruber and a cyclase/O-methyltransferase from Streptomyces glaucescens. Tetrahedron 47, 6029-6043.

Sherman, D. H., Malpartida, F., Bibb, M. J., Kieser, H. M., Bibb, M. J. \& Hopwood, D. A. (1989). Structure and deduced function of the granaticin-producing polyketide synthase gene cluster of Streptomyces violaceoruber Tü22. EMBO J 8, 2717-2725.

Strauch, E., Takano, E., Baylis, H. A. \& Bibb, M. J. (1991). The stringent response in Streptomyces coelicolor A3(2). Mol Microbiol 5, 289-298.

Stutzman-Engwall, K. J. \& Hutchinson, C. R. (1989). Multigene families for anthracycline antibiotic production in Streptomyces peucetius. Proc Natl Acad Sci US A 86, 3135-3139.

Stutzman-Engwall, K. J., Otten, S. L. \& Hutchinson, C. R. (1992). Regulation of secondary metabolism in Streptomyces spp. and overproduction of daunorubicin in Streptomyces peucetius. J Bacteriol 174, 144-154.

Swan, D. G., Rodríguez, A. M., Vilches, C., Méndez, C. \& Salas, J. A. (1994). Characterisation of a Streptomyces antibioticus gene encoding a Type I polyketide synthase which has an unusual coding sequence. Mol Gen Genet 242, 358-362.

Westrich, L., Domann, S., Faust, B., Bedford, D., Hopwood, D. A. \& Bechthold, A. (1999). Cloning and characterization of a gene cluster from Streptomyces cyanogenus S136 probably involved in landomycin biosynthesis. FEMS Microbiol Lett 170, 381-387.

Wietzorrek, A. \& Bibb, M. (1997). A novel family of proteins that regulates antibiotic production in streptomycetes appears to contain an OmpR-like DNA-binding fold. Mol Microbiol 25, 1177-1184.

Wright, F. \& Bibb, M. J. (1992). Codon usage in the $G+T$ rich Streptomyces genome. Gene 113, 55-65.

Yanisch-Perron, C., Vieira, J. \& Messing, J. (1985). Improved M13 phage cloning vectors and host strains: nucleotide sequences of the M13mp18 and pUC19 vectors. Gene 33, 103-119.

Zaballos, A., Salas, M. \& Mellado, R. P. (1987). A set of expression plasmids for the synthesis of fused and unfused polypeptides in Escherichia coli. Gene 58, 67-76.

Received 15 December 2000; revised 21 May 2001; accepted 23 July 2001. 